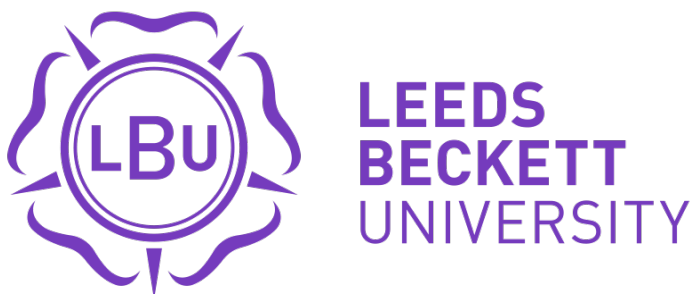

Citation:

Beggs, CB and Knibbs, LD and Johnson, GR and Morawska, L (2015) Environmental contamination and hospital-acquired infection: factors that are easily overlooked. Indoor air, 25 (5). 462 - 474. ISSN 0905-6947 DOI: https://doi.org/10.1111/ina.12170

Link to Leeds Beckett Repository record:

https://eprints.leedsbeckett.ac.uk/id/eprint/2372/

Document Version:

Article (Accepted Version)

The aim of the Leeds Beckett Repository is to provide open access to our research, as required by funder policies and permitted by publishers and copyright law.

The Leeds Beckett repository holds a wide range of publications, each of which has been checked for copyright and the relevant embargo period has been applied by the Research Services team.

We operate on a standard take-down policy. If you are the author or publisher of an output and you would like it removed from the repository, please contact us and we will investigate on a case-by-case basis.

Each thesis in the repository has been cleared where necessary by the author for third party copyright. If you would like a thesis to be removed from the repository or believe there is an issue with copyright, please contact us on openaccess@leedsbeckett.ac.uk and we will investigate on a case-by-case basis. 


\section{Environmental contamination and hospital acquired infection: factors that are easily overlooked}

Clive Beggs ${ }^{1 *}$, Luke D. Knibbs², Graham R. Johnson³ ${ }^{3}$ Lidia Morawska ${ }^{3}$

${ }^{1}$ Centre for Infection Control and Biophysics, University of Bradford, Bradford, UK ${ }^{2}$ School of Population Health, The University of Queensland, Herston, QLD 4006, Australia

${ }^{3}$ International Laboratory for Air Quality and Health, Queensland University of Technology, Brisbane, QLD 4001 Australia

${ }^{*}$ Corresponding Author:

Prof Clive Beggs

Centre for Infection Control and Biophysics

School of Engineering, Design \& Technology

University of Bradford

Bradford

West Yorkshire

BD7 1DP

United Kingdom

email: c.b.beggs@bradford.ac.uk, Tel: +44(0)1274 233679, Fax: +44(0)1274 234124 


\title{
Environmental contamination and hospital acquired infection: factors that are easily overlooked
}

\begin{abstract}
There is an ongoing debate about the reasons for, and factors contributing to healthcare-associated infection (HAl). Different solutions have been proposed over time to control the spread of $\mathrm{HAl}$, with more focus on hand hygiene than on other aspects such as preventing the aerial dissemination of bacteria. Yet, it emerges that there is a need for a more pluralistic approach to infection control; one that reflects the complexity of the systems associated with HAI, and involves multidisciplinary teams including hospital doctors, infection control nurses, microbiologists, architects, and engineers with expertise in building design and facilities management. This paper reviews the knowledge base on the role that environmental contamination plays in the transmission of $\mathrm{HAl}$, with the aim of raising awareness regarding infection control issues that are frequently overlooked. From the discussion presented in the paper it is clear that many unknowns persist regarding aerial dissemination of bacteria, and its control via cleaning and disinfection of the clinical environment. There is a paucity of good quality epidemiological data, making it difficult for healthcare authorities to develop evidence-based policies. Consequently, there is a strong need for carefully designed studies to determine the impact of environmental contamination on the spread of HAI.
\end{abstract}




\section{Environmental contamination and hospital acquired infection: factors that are easily overlooked}

\subsection{Introduction}

In recent years there has been awareness that microbial contamination of the clinical environment may contribute to the spread of healthcare-associated infection (HAl) (Dancer et. al. , 2009, Dancer, 2004, Dancer, 2008, Boyce et. al. , 1997). Consequently, there has been increased emphasis on surface disinfection and ward cleaning, with some authorities placing a statutory obligation on hospitals to ensure that the clinical environment is clean and well maintained (N.P.S.A, 2007). While this has made the cleaning and disinfection of hospital wards a higher priority, the role that environmental contamination plays in the transmission of HAl is poorly understood. Indeed, there is little firm epidemiological evidence to support the widelyheld and intuitive belief that cleaner hospitals result in fewer infections (Dancer et. al., 2009, Dancer, 2008, Rhame, 1998). There is however, considerable evidence that the touching of contaminated surfaces by healthcare workers ( $\mathrm{HCWs)} \mathrm{frequently}$ results in the transient colonization of hands or gloves (Duckro et. al. , 2005, Boyce et. al., 1997, Hayden et. al. , 2008, Bhalla et. al. , 2004, Ray et. al. , 2002), suggesting that there is a link between surface contamination and transient colonisation of the hands of HCWs. In fact, numerous studies have implicated contamination of the clinical environment in outbreaks of Gram-positive (MalamouLadas et. al. , 1983, Hota, 2004, Fawley and Wilcox, 2001, Kumari et. al. , 1998, Hardy et. al. , 2006, Cotterill and al., 1996) and Gram-negative (Beggs et. al. , 2006a, Das et. al. , 2002, Weernink et. al. , 1995, Allen and Green, 1987, Sherertz and Sullivan, 1985, McDonald et. al. , 1998, Breathnach et. al. , 2012, Engelhart et. al. , 2002) bacterial infection. However, while much effort has been expended investigating environmental contamination and $\mathrm{HAI}$, most of this has been detective work undertaken in response to specific hospital outbreaks. By comparison, very few controlled trials have been undertaken, with the result that the contribution made by environmental contamination to the overall body of $\mathrm{HAl}$ is difficult to quantify and characterize. It is therefore difficult to address with confidence, even basic questions regarding the cleanliness of hospitals. For example, it is not known which ward surfaces should be cleaned or disinfected, and how often such cleaning is required in order to minimise HAl rates. Indeed, it is not known if heavily contaminated surfaces such as hospital ventilation ducts, (which can accumulate particulate debris to a depth of several millimetres) pose any threat to the safety of patients. Consequently, 
healthcare authorities have great difficulty specifying meaningful performance criteria for general hospital cleanliness.

To explore the role of environmental contamination in the transmission of infection within healthcare facilities, this paper aims to highlight infection control issues relating to building design and facilities management that have been overlooked, but might be worthy of further investigation. We limit our scope to sources of bacterial and fungal infection, as these have been more extensively described in the literature than viral pathogens.

\subsection{Gulf between disciplines}

Traditionally, infection control has been the sole preserve of hospital doctors, infection control practitioners and microbiologists. However in recent years other professionals such as engineers have become involved in infection control, primarily because of their expertise in building design, facilities management, and modelling airflows within and between room spaces. In addition, many commercial organizations have developed hygiene related products for use in the healthcare sector. This increased activity has led to new insights into the transmission of some HAls. However, while engineers and physical scientists have been able to make significant contributions to the infection control knowledge base, a gulf in thinking still exists between these professionals and hospital clinicians. This gulf reflects the various approaches inherent in these different occupations and is exemplified by a general belief amongst clinicians that the battle against HAI can be won only through greater hand hygiene compliance. Conversely, engineers and manufacturers tend to believe that gadgets and technical fixes might offer the optimum solution. This has polarized the debate, with clinicians tending to be very sceptical of infection control strategies not primarily focused on hand hygiene compliance, despite the fact that several studies have shown that the efficacy of hand hygiene measures can be severely limited by other factors (Beggs et. al. , 2008b, Beggs et. al. , 2006b, Talon et. al. , 2009, Silvestri et. al. , 2005, Beggs et. al. , 2009, DiDiodato, 2013). A middle ground between the two viewpoints that takes a 'whole of system' approach to HAI control would be able to capitalise on the expertise of all involved. Unfortunately, this has been conspicuous in its absence to date. 


\subsection{Complexity of the systems associated with HAl}

HAls arise from complex systems influenced by many factors, not the least of which are the biological characteristics of the infectious agents involved. In particular, the logistics associated with the management of patients and staff appear to be critical (Beggs et. al., 2006b). This complexity has largely been ignored by many in the infection control community, with the result that there has been a tendency to rely on single-measure strategies rather than taking a more holistic approach. However, the evidence suggests that single-measure strategies are not sufficient and that a more multi-faceted approach is required. Take for example the contrasting experiences of the health services in the Netherlands and UK. The Netherlands was quick to introduce a search-and-destroy (S\&D) policy to counteract the emergence of drug resistant bacteria such as methicillin-resistant $S$. aureus (MRSA). The S\&D policy was introduced as soon as cases of methicillin resistance were reported, although no official protocol existed until 1989 (Dekker and Van Den Broek, 2010). As the name implies, the Dutch authorities employed a comprehensive strategy that sought to isolate, contain and destroy MSRA whenever an infection was suspected or diagnosed. As such, the main focus of the strategy was on the screening and isolation of patients considered to be at increased risk for the carriage of MRSA (van Rijen and Kluytmans, 2009). All suspected patients were isolated and only released if cultures proved negative. When cultures were positive, the bacteria were first eradicated before the patient was released. In addition, hospital employees that had unprotected contact with MRSA positive patients were screened and prohibited from returning to work until they were culture negative (Dekker and Van Den Broek, 2010). This S\&D strategy proved to be highly effective, maintaining the level of bacteraemia caused by MRSA at very low levels $(\leq 1 \%)$ compared with other European countries that in some cases reached levels of up to $50 \%$ (Tiemersma et. al. , 2005). Similar screening and isolation strategies were adopted by healthcare trusts in the UK, but these were relaxed or abandoned in 1995 because of a lack of suitable isolation rooms, and also because ward closures and the cohorting of staff and patients caused considerable clinical disruption (Farrington et. al. , 1998). Instead, the UK focused on hand hygiene measures alone to fight MRSA - a policy encapsulated in the Cleanyourhands campaign (Stone et. al. , 2012). Unlike the Dutch experience, this policy resulted in a steady year-on-year increase in deaths associated with MRSA in England and Wales from 1993 to 2006, peaking at >1600 in 2006 (Pearson, 2009). Likewise, deaths associated with Clostridium difficile rose steadily from $<1000$ 
in 1999 to >8000 in 2007 (Pearson, 2009). While there is some evidence that the Cleanyourhands campaign, initiated in 2004, was responsible for stopping the steady rise of HAls (Stone et. al., 2012), it was not until a raft of additional infection control measures were introduced around 2007 that HAI rates began to fall. With the introduction of care bundles (i.e. simple infection control guidelines for placing catheters, invasive lines and ventilator tubes); widespread deep cleaning of wards; cohorting of staff and patients; and improved screening of patients; MRSA and C. difficile infection rates fell by $>50 \%$ (H.P.A., 2012b, H.P.A., 2012a). Collectively, these measures highlight the need for a more pluralistic approach to infection control; one that reflects the complexity of the systems associated with HAI.

\subsection{Aerial dissemination}

One interesting difference between the Dutch and British approaches to the control of MRSA is that the former assumed that MRSA can be disseminated by the airborne route, whereas the latter did not, as this route of transmission is generally not considered to be of great importance. Consequently, in the Netherlands MRSA isolation rooms are required to have an antechamber and to be negatively pressurized (van Rijen and Kluytmans, 2009), whereas in the UK, patients colonized with MRSA tend to be barrier nursed through placement in ward side rooms and the implementation of additional precautions to prevent the spread of infection. The differences between the approaches taken in the UK and Netherlands, highlights the tension that exists regarding the airborne transmission of infection in hospitals (Beggs, 2003a) - something that clinicians in many countries believe is of negligible importance compared to the spread of infection via the handborne route (Rhame, 1998, Ayliffe et. al. , 1999). Yet there is a large body of evidence, which suggests that both Gram-negative and Gram-positive pathogens are frequently disseminated by the aerial route in the clinical environment. Contaminated clothing and bedding of colonized patients release $S$. aureus into the air when disturbed (Solberg, 1965, Shiomori et. al. , 2002, Noble and Davies, 1965). Bed-making in particular liberates large numbers of particles (Roberts et. al. , 2006), many of which carry staphylococci into the air and these are then deposited on surfaces within the environment (Shiomori et. al. , 2001, Shiomori et. al., 2002, Noble, 1962). For example Rutala et al (Rutala et. al. , 1983) investigated a MRSA outbreak in a burn unit and found that MRSA accounted for $16 \%$ of all bacterial isolates sampled from the air, and $31 \%$ of the isolates cultured from elevated surfaces. In another study Shiomori et al 
(Shiomori et. al., 2002), sampling the environment around MRSA colonized and infected patients under normal conditions, found an average of $4.7 \mathrm{cfu} / \mathrm{m}^{3} \mathrm{MRSA}$ carrying particles in the air near infected patients; however during bed making this figure increased to $116 \mathrm{cfu} / \mathrm{m}^{3}$, confirming that this activity results in considerable aerosolization of particles containing staphylococci. Similarly, it has been demonstrated that Acinetobacter spp. (Houang et. al. , 2001, Beggs et. al., 2006a, Allen and Green, 1987, Das et. al., 2002, Gerner-Smidt, 1987, Obbard and Fang, 2003, Thornton et. al. , 2004) and C. difficile (Roberts et. al. , 2008) can be readily disseminated into the clinical environment by the aerial route. The different levels of recognition and acknowledgement of such evidence supporting airborne dissemination in the Netherlands and UK may have been a key factor in determining their relative success.

\subsection{Surface contamination due to aerial dissemination}

The extent to which aerial dissemination of bacteria contributes to surface contamination in hospitals has received little attention. Of the few studies undertaken, most have been carried out under controlled conditions in aerosol chambers (King et. al. , 2013, Hathway et. al. , 2007, Wong et. al. , 2010), with only a handful of studies linking particle dissemination with clinical activities (Roberts et. al., 2006, Hathway et. al. , 2011, Ayliffe et. al., 1999, Greene et. al. , 1960). Consequently, while it is known that aerial dissemination can result in surface contamination, there is little quantitative data on deposition rates and their variation, with which to make clinical judgments. It is however possible to make a rough estimate of particle deposition rates based on published data and using reasonable assumptions. For example, consider a $10 \times 8 \times 2.7 \mathrm{~m}$ ward room containing four patients (ignoring the presence of visitors, doctors, nurses, etc.), which experiences a ventilation rate of six air changes per hour. Based on earlier work by Roberts and Marks (Roberts and Marks, 1980), Milstone (Milstone, 2004) estimated that humans shed between $2 \times 10^{8}$ and $10 \times 10^{8}$ skin squamae per day, which equates to a combined average liberation rate of between 9259 and 46296 squamae per second for the four patients on the ward. If the air in the room space is well mixed and the squamae evenly distributed, then the calculated steady-state mean concentration of skin squamae in the air would be in the range 25719 to 128600 squamae $/ \mathrm{m}^{3}$. If it is then conservatively estimated that each squamae carries 10 bacteria (Lundholm estimated that squamae frequently 
carry >100 bacteria (Lundholm, 1982)), we arrive at a theoretical steady-state figure of 257190 to 1286000 bacteria $/ \mathrm{m}^{3}$ of air, which is of a similar order of magnitude to that found by Toivola et al (Toivola et. al. , 2004). If only $10 \%$ of the bacteria carrying particles deposit at an average rate of $2 \mathrm{~mm} / \mathrm{s}$ (the settling velocity of an $8 \mu \mathrm{m}$ particle), then a conservative estimate of the deposition rate would be of the order 51 to 257 bacteria $/ \mathrm{m}^{2}$ per second. Of course, in reality, the particles would not be evenly distributed throughout the room space, or shed at a constant rate; rather, they would be liberated into the air periodically in great numbers during bed making and other activities. This calculation should therefore be treated with caution. Notwithstanding this, this crude calculation does serve to illustrate an important and much over-looked point; namely, that aerial dissemination must be responsible for widespread surface contamination within the clinical environment. Evidence supporting this supposition comes from a 22-month surveillance study in which air vents and high horizontal surfaces were found to be contaminated with $C$. difficile, suggesting the aerial dissemination of isolates (Fawley and Wilcox, 2001, Fawley et. al. , 2003). Furthermore, outbreak strains of MRSA are frequently recovered from elevated surfaces (Rutala et. al., 1983) that are unlikely to have been touched by healthcare personnel, indicating that staphylococci must be transported through the air. Indeed, Boyce et al (Boyce et. al., 1997) found that patients colonized/infected with MRSA frequently contaminated room surfaces, with environmental contamination occurring in the rooms of $73 \%$ of MRSA-infected patients.

\subsection{Gram negative bioaerosols}

Immunocompromised patients in intensive care, high dependency, burns and haematology/oncology settings are particularly vulnerable to infection, many of which are associated with Gram-negative bacteria. These bacteria are strongly hydrophilic and are frequently cultured from sinks and wash hand basins in hospital wards (de Abreu et. al. , 2014, Kotsanas et. al. , 2013, Trautmann et. al. , 2001). There is increasing evidence that these microorganisms can become readily aerosolized. For example, Doring et al. (Doring et. al. , 1991) found sinks and basins on a hospital ward to act as reservoirs for Pseudomonas aeruginosa, with the result that the opening of water taps (faucets) generated bioaerosols containing $P$. aeruginosa, which contaminated the hands of HCWs during hand washing. An outbreak in a nursery was traced to a new air-conditioning system, from which Acinetobacter spp. Isolates were cultured (McDonald et. al., 1998). It was surmised that the outbreak 
was caused by the dissemination of a bioaerosol generated by the contaminated airconditioning unit. Contaminated air-conditioning units have also been implicated in outbreaks of $P$. aeruginosa infection (Pinna et. al. , 2009). Interestingly Ryan et al (Ryan et. al. , 2011) showed that by installing germicidal ultraviolet irradiation in the air conditioning system on a neonatal intensive care unit (NICU), it was possible to greatly reduce the incidence of ventilator-associated pneumonia (VAP).

The problem of Gram-negative bioaerosols becomes acute when the aerosols generated are specifically associated with medical equipment. With respect to this, the humidifiers and nebulizers associated with patient ventilator systems are particularly vulnerable (Jadhav et. al. , 2013). When contaminated, they can 'inject' bioaerosols directly into the respiratory system, causing ventilator-associated pneumonia. Contaminated ventilator humidifiers and nebulizers have been implicated in outbreaks of Pseudomonas (Phillips, 1967, Redding and McWalter, 1980) and Acinetobacter (Cefai et. al. , 1990, Ebenezer et. al. , 2011). Portable medication nebulizers have also been implicated in infections of Legionella pneumophila (Mastro et. al. , 1991), Burkholderia Cepacia (Hutchinson et. al. , 1996) and Stenotrophomonas maltophilia (Denton et. al. , 2003). These items of equipment require frequent washing/cleaning, and in the case of humidifiers, filling with sterile water, and are therefore vulnerable to contamination. Sinks and wash hand basins can act as reservoirs for Gram-negative pathogens, and a number of studies have implicated contaminated water supplies with increased risk of ventilator/nebulizer related infection (Mastro et. al., 1991, Lucero et. al. , 2011, Jarvis et. al. , 2014).

\subsection{Ward cleanliness}

Given that aerial dissemination of bacteria must be widespread in hospitals, why then is more attention not paid to this phenomenon? The simple answer to this question is that the clinical relevance of aerial dissemination is not well understood and therefore it is not considered a major problem. Outside of a few countries, notably the Netherlands and some Scandinavian countries, aerial dissemination of bacteria appears to have been largely ignored. One reason for this indifference is that the whole subject of ward cleanliness has generally been viewed as being of secondary importance compared with hand hygiene compliance. While the general public might associate visibly dirty wards with the transmission of MRSA infection, rather surprisingly there is relatively little epidemiological evidence that the environment is 
important in endemic HAl (Rhame, 1998, Dancer et. al., 2009, Dancer, 2008, Maki et. al. , 1982, Collins, 1988, McGowan, 1981). Indeed, in a 2007 paper (Boyce et. al., 1997), the eminent microbiologist JM Boyce felt compelled to start his paper with the words: "For several decades, there has been considerable controversy over whether or not contaminated environmental surfaces contribute to transmission of healthcareassociated pathogens." Given that contaminated surfaces can readily contaminate the hands of HCWs (Boyce et. al., 1997, Hayden et. al., 2008, Bhalla et. al., 2004, Ray et. al., 2002, Duckro et. al., 2005), one might wonder why there is any controversy. However, while it is relatively easy to show that colonized and infected patients can readily contaminate the clinical environment, it is much more difficult to demonstrate causality in the reverse direction. Consequently, epidemiological evidence supporting the link between ward cleanliness and HAI has been hard to obtain, with the result that healthcare authorities, hard-pressed by financial constraints, have tended to reduce the numbers of cleaners employed and the hours worked (Dancer, 2008). Furthermore, because the evidence base is sparse, cleaners specifications often focus on the cleaning of the most visible and widely-accepted locations like floors and toilets, rather than cleaning near-patient hand-touch sites, such as bed rails, bedside lockers, and infusion pumps, which are more likely to be of clinical importance (Dancer, 2008). As a result, cleaning of these near-patient surfaces may all too easily be overlooked.

In 2007, partly due to political pressure, but also due recognition that existing infection control policies had failed, the Department of Health in the UK rolled out a comprehensive hospital deep cleaning programme (D.O.H., 2008). At approximately the same time they also introduced a new national specification for hospital cleanliness (N.P.S.A, 2007) and imposed a statutory obligation on healthcare trusts to provide and maintain a clean clinical environment (N.P.S.A, 2007) - a noticeable departure from previous policy. Interestingly, the introduction of this policy coincided with a marked reduction in reported MRSA bacteraemia cases, which in England and Wales fell from 4451 in 2007-08 to 1114 in 2011-12 (H.P.A., 2012b) - something that was matched by a similarly large reduction in $C$. difficile associated infections (H.P.A., 2012a). This raises an obvious question about the extent to which the change in policy contributed to the reduction in HAI rates. However, this question is not easy to answer, because along with improved cleanliness, the Department of Health also introduced a raft of other measures, including improved strategies for placing and monitoring catheters and invasive lines, together with a continued push to improve hand hygiene compliance (Cleanyourhands campaign). Indeed, Stone et 
al (Stone et. al., 2012) attributed the reductions in MRSA and C. difficile infection rates almost entirely to the Cleanyourhands campaign, which was commenced in 2004 - despite the fact that $C$. difficile infection rates did not start to fall until 2007. Noticeably, no mention was made, or analysis undertaken, of the contribution of improved ward cleanliness to the reduction in infection rates. Consequently, while intuitively one might feel that environmental contamination must influence HAI rates, concrete epidemiological evidence to this effect remains elusive due to the difficulty in disentangling the role of other factors. Notwithstanding this, there is evidence that hardy pathogens, such as $S$. aureus can be widely disseminated throughout the clinical environment via the hands of HCWs. Oelberg et al (Oelberg et. al. , 2000) using a viral DNA marker to inoculate a single telephone in a neonatal intensive care unit (NICU), observed that inanimate surfaces throughout the NICU rapidly became contaminated, with the number of positive sites peaking after only 8 hours. Similarly, Duckro et al (Duckro et. al., 2005) found vancomycin-resistant enterococci (VRE) to be rapidly disseminated around the clinical environment via HCW-surface interactions. Furthermore, Wilson et al (Wilson et. al. , 2004) observed a strong correlation between the presence of MRSA-colonized or -infected patients and air samples yielding MRSA in an ICU, suggesting widespread aerial dissemination. Given that contact with contaminated surfaces can readily lead to transient colonization of the hands of HCWs (Boyce et. al., 1997), there is good reason to believe that hospital cleanliness is likely to have an impact on HAI rates.

\subsection{Hospital ventilation and duct contamination}

Most modern hospital buildings utilize mechanical ventilation air conditioning systems in order to maintain a comfortable environment for patients and staff. These systems contain large stretches of ductwork in which particulate matter can deposit and accumulate. Consequently, ducts in hospitals can become highly contaminated (see Figure 1). In recent years concern has been expressed about the risks posed by contaminated mechanical ventilation ductwork in hospital buildings. Yet, relatively little research has been carried out into the health risks associated with contaminated ventilation ductwork, particularly in healthcare facilities, with the result that little epidemiological evidence exists. 


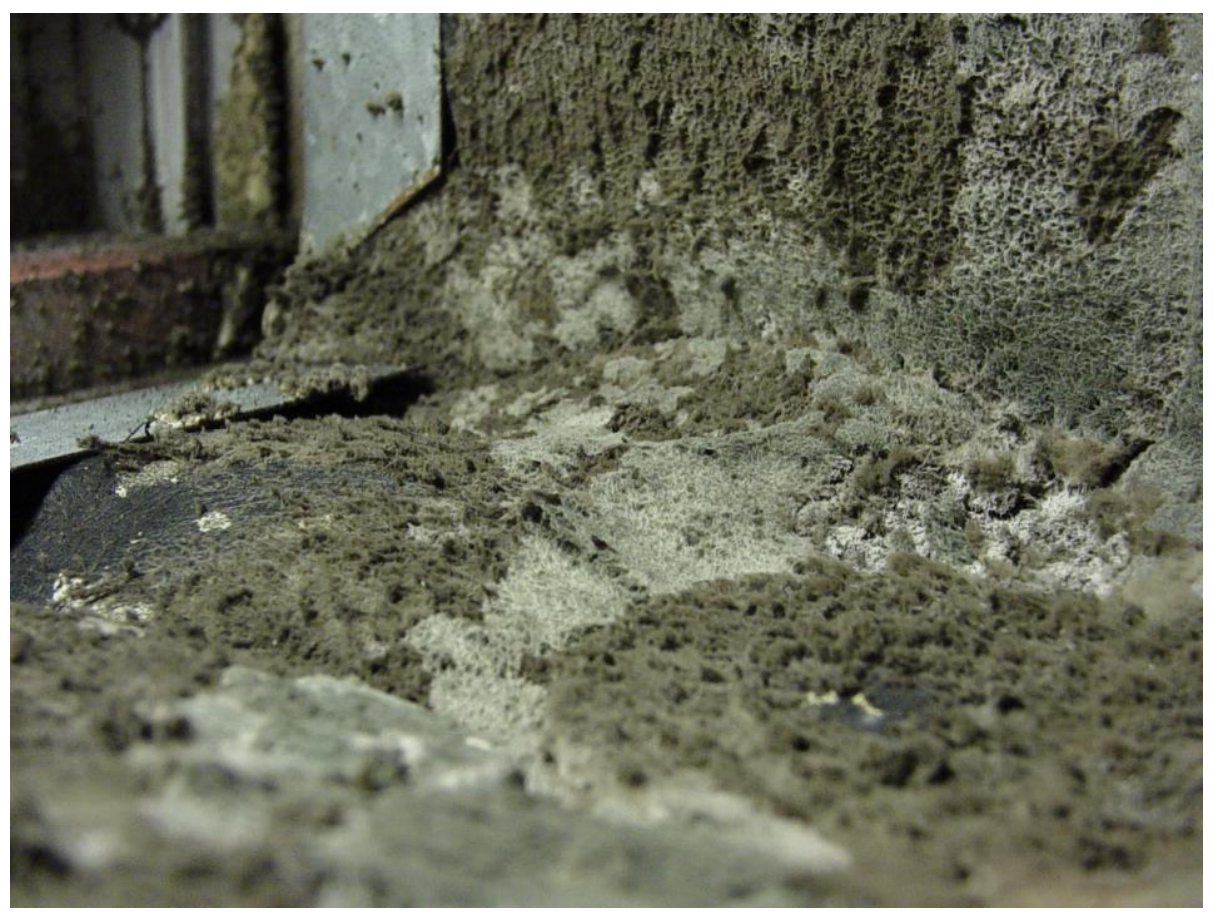

Figure 1. Typical example of a highly contaminated mechanical ventilation duct. Image courtesy of Total Ventilation Hygiene Pty Ltd and licensed for use in the HB2012 presentations and associated media.

While both supply and extract ducts may become heavily contaminated, in hospital buildings it is important to distinguish between the two, because the nature of the contamination is likely to be very different in the two types of ductwork. In supply ducts, because the air comes from a mixture of outdoor and filtered return air, fungal species are likely to predominate, whereas in the return air ducts, which extract from the ward spaces, contamination is likely to be predominately bacterial in nature. Of course, if the air is recirculated, as is the case in some healthcare facilities, then the bacterial pathogens from the ward space, such as MRSA, are likely to contaminate the supply duct and this might pose a greater hazard. Dust from occupied sections of buildings is largely comprised of skin squamae, and can accumulate in return ducts, especially when the air velocity is low (Batterman and Burge, 1995). It is therefore important when considering the subject of ductwork contamination to also consider the type of ventilation system in use, as this may have a bearing on the risk. Clearly if the recirculation of room air is permitted, then there is a greater likelihood of bacterial pathogens, being widely distributed around a healthcare facility via the mechanical ventilation system. Indeed, a number of studies relating to the transmission of 
tuberculosis have shown this to be the case (Nardell et. al. , 1991, Beggs, 2003b, Houk, 1980).

Guidelines regarding the recirculation of air in healthcare settings vary greatly (Beggs et. al. , 2008a). For example, the American Institute of Architects (AIA) guidelines permit recirculation of ward air (A.I.A., 2001), whereas those for the United Kingdom in HTM 03 strongly discourage the use of recirculation systems (D.O.H., 2007). Because recirculation of air is permitted, in the United States the air supplied to patients in general wards must be first pre-filtered (minimum efficiency reporting value [MERV] 7, 30\% dust spot efficiency), and then filtered to a MERV 14 or 15 standard (90\% to $95 \%$ dust spot efficiency) before delivery to the ward space (A.S.H.R.A.E., 2003). This standard of filtration ensures $85 \%$ to $95 \%$ collection efficiency for 0.3 to $1.0 \mu \mathrm{m}$ particles and $>90 \%$ efficiency for $>1.0 \mu \mathrm{m}$ particles. Given that skin squamae are generally 4 to $25 \mu \mathrm{m}$ in size, this level of filtration should ensure that the air supplied to the ward space is relatively clean, despite the fact that a large proportion of this air may be recirculated. By comparison in the United Kingdom, where ward mechanical ventilation systems tend to be full fresh air, HTM 03 simply specifies the use of EU4 filters (>90\% synthetic dust weight arrestance) in the supply air ducts to general ward spaces. Such filters are capable of removing the larger, heavier particles found in outdoor air. For critical care settings EU7 filters (80$90 \%$ dust spot efficiency) are specified, reflecting the higher perceived risk to patient safety in these areas (D.O.H., 2007).

\subsection{Ductwork contamination}

Given that heavily contaminated ductwork such as that shown in Figure 1 can be found in hospital buildings, one might naturally assume that it poses a significant health hazard. However, the reality is that there are very little data directly relating environmental contamination of this type to adverse health effects (Kuehn, 2003). One reason for this might be that mechanical ventilation systems effectively act as a sink removing microbial particles from ward air - in effect, they act like a giant filter. If microbial particles are deposited within a ductwork system, then by definition they are removed from the air stream that enters the ward space. So in effect, the ductwork traps larger airborne particles preventing them from being distributed around the clinical environment. While the retention of particles might be considered beneficial, there is also a potential downside. If microbial particles from the ductwork become re- 
suspended in the air for any reason, then they will be readily dispersed into the ward spaces. While relatively little is known about the re-suspension of bacterial matter, the same cannot be said for fungal spores that are uniquely adapted for aerial dissemination. Unlike bacterial matter, which generally requires the intervention of some mechanical force to create an aerosol, fungal spores are naturally disseminated by the airborne route, and so can easily re-enter the air stream within ventilation ducts. Given that hospital air conditioning and ductwork systems can become heavily contaminated with nosocomial fungal pathogens, such as Aspergillus species (Lutz et. al. , 2003, Curtis et. al. , 2005, Lentino et. al. , 1982), there is reason to believe that ductwork colonized with fungal species might pose an infection risk, especially to immunocompromised patients (Buttner et. al. , 1999).

There is evidence implicating contaminated ventilation systems with fungal infections in immunocompromised patients. Walsh and Dixon (Walsh and Dixon, 1989) cited contaminated ventilation systems as a common source of invasive aspergillosis, while Lentino et al (Lentino et. al., 1982) implicated contaminated window mounted air conditioning units in an outbreak of pulmonary aspergillosis. In another study, Lutz et al (Lutz et. al., 2003) identified mold contamination in an operating theatre airhandling system as the source of Aspergillus infections amongst post-surgical patients. They found that insulation material in variable-air-volume (VAV) units had become wet and had subsequently become colonized with several Aspergillus species. Insulation and filter media appear particularly vulnerable to fungal degradation when wet or under conditions of high humidity. Simmons and Crow (Simmons and Crow, 1995) found substantial growth of Aspergillus species on cellulosic filters at relative humidities $>70 \%$, and Maus et al (Maus et. al. , 2001) observed significant growth of Aspergillus niger on used filters at relative humidities $>85 \%$.

With regard to the aerial dissemination of Aspergillus conidia, the case study described by Lutz et al (Lutz et. al., 2003) highlights the importance of using terminal filtration in locations where immunocompromised patients might be vulnerable to infection. In this case, Lutz et al identified the fact that VAV units were mounted downstream of final filters as an issue of concern. When the insulation material in the ductwork became damp and degraded there was no barrier to filter the spores, and they were readily disseminated into the operating theatre. Given that Aspergillus conidia have diameters in the region 2-4 $\mu \mathrm{m}$ (Lutz et. al., 2003), somewhat smaller than skin squamae, it may be necessary to install high-performance terminal filtration 
if the dissemination of spores is to be prevented - something highlighted in a study by Oren et al (Oren et. al. , 2001) who reported on an outbreak of pulmonary aspergillosis associated with construction activity. They found that airborne concentrations of Aspergillus species rose to a mean value of $15 \mathrm{cfu} / \mathrm{m}^{3}$ in wards near a construction site. However, the installation of high-efficiency particulate air (HEPA) filters in hematological ward reduced the mean count to $0.18 \mathrm{cfu} / \mathrm{m}^{3}$ and eliminated invasive pulmonary aspergillosis completely.

\subsection{Ductwork cleaning}

Concerns regarding potential infection risks posed by contaminated ducting have led to a rise in the number of contractors offering specialist ductwork cleaning services to healthcare authorities. However, the evidence base of the efficacy of these measures in hospitals is limited. A somewhat larger body of evidence exists in relation to duct cleaning in residential and non-industrial commercial buildings, and this was recently reviewed with an aim of answering the question: is ventilation duct cleaning useful? (Zuraimi, 2010). The review, which employed strict inclusion criteria to assure that only peer reviewed, well designed and relevant papers were considered, came to several important conclusions. It firstly confirmed the existence of evidence that ventilation ducts are often contaminated with dust and provide conditions for microbiological growth, and that this happens under normal operating conditions. However, no field studies have conclusively correlated concentration of indoor pollution with duct contamination, despite controlled experiments showing that there is a plausible basis for this happening. The review also examined the available duct cleaning methodologies and showed that some of them are very efficient. However, again, it was unable to find consistent evidence that there is an improvement in indoor air quality after cleaning of the ducts. In fact, some of studies concluded that the opposite is the case, and that post-cleaning indoor concentrations are higher than pre-cleaning.

There is a disparity between the lack of evidence that duct cleaning can improve occupants' health or symptoms, and some suggestive evidence from epidemiological studies highlighting the association of dirty ducts with higher risk of symptoms. In general, the review demonstrated that that there is a need for balance between duct cleanliness and negative effects related to the process of cleaning. Nevertheless, the study demonstrated that the body of the evidence on many of the aspects discussed 
is still small and identified specific areas requiring further research. While there are large differences between residential and commercial buildings in their purpose, design and operation, it is expected that the general conclusion on duct cleaning in such buildings is also generally applicable to hospital buildings, and that the knowledge gaps on the impact of duct cleaning in hospital building are even greater. Consequently, because the evidence base is sparse, healthcare authorities find it difficult to develop objective standards.

Most parts of ventilation systems can support microbial growth (Batterman and Burge, 1995), but frequently damp sections of ventilation air handling equipment and ducting most effectively promote mold growth, particularly Aspergillus fumigatus and Aspergillus flavus. This is especially true in areas where the primary role of the air handler is cooling, leading to substantial water condensation (Horner, 2006). These species are also present in accumulated dust inside ducts. There is evidence to suggest that mechanical brushing is more efficient at removing such dust from metal ducts and compressed air cleaning is more efficient for plastic ducts, and that reductions of 75 to $94 \%$ in surface dust levels can be achieved under field conditions (Holopainen et. al. , 2003). Of course, it is critical that the potential for resuspension of colonized dust and its liberation into supply air be minimized. Most mechanical brushing systems also incorporate a vacuum collection device, but there is potential for fugitive dust to reach indoor areas (Zuraimi, 2010). Chemical disinfection treatments (biocides, ozone, etc.) may be required to deal with substantial fungal and bacterial growth. However, these can pose a potential health risk in their own right (Zuraimi, 2010). The health risk-benefit balance for duct cleaning is not clear, at least in non-healthcare indoor environments (Zuraimi, 2010). Given the specific nature of healthcare settings, the large number of potential infection sources within them, and the susceptible nature of their occupants, it is plausible that carefully performed and appropriate duct cleaning could reduce HAI risk. However, the evidence base on this topic is very limited, and there is a strong need for well-performed studies linking duct cleaning with health outcomes. In the meantime, it is prudent to prevent or limit microbial contamination in the first instance, through the use of ultraviolet germicidal irradiation (UVGI) in air handlers and ducting, for example (Horner, 2006). 


\subsection{Discussion and Conclusions}

The discussion above highlights the considerable hole in the knowledge base regarding the role that environmental contamination plays in the transmission of HAI. Not only is there no agreement on the risks posed by specific issues such as ductwork contamination, there is little quantifiable evidence regarding the benefits, or otherwise, of cleaning and disinfecting hospital wards, despite a general consensus that it is probably a good thing to do. Because it is difficult to quantify, the impact of hospital cleanliness is easily ignored. For example, the substantial fall in HAls in the UK since 2007 has been attributed by some (Stone et. al., 2012), almost entirely to the Cleanyourhands campaign, despite the introduction of care bundles and hospital deep cleaning at approximately that time. Although hand hygiene is a key infection control measure of great importance, there is growing evidence that a multi-faceted approach is necessary. Evidence from several mathematical simulation studies (Beggs et. al., 2006b, Beggs et. al., 2008b, Beggs et. al., 2009) suggests that poor hand hygiene compliance is only one factor in the spread of $\mathrm{HAI}$, and that other factors must be at work. In particular, the benefits of hand hygiene compliance appear to be threshold limited (Beggs et. al., 2008b, Beggs et. al., 2009). Indeed, a recent large Canadian study involving 166 acute care hospitals (DiDiodato, 2013) found that despite significant improvements in reported rates of hand hygiene compliance amongst healthcare personnel, no consistent reduction in either $C$. difficile infections or MRSA bacteremia was achieved. This prompted the study's author to state: "This study supports the emerging evidence that once a threshold level of hand hygiene compliance is achieved, there is very little if any benefit to attempting to achieve higher rates of hand hygiene compliance among healthcare providers." The UK experience since 2007 would tend to support this opinion. The introduction of a multi-faceted approach involving the introduction of: patient screening; cohorting of patients and nurses; careful use of antibiotics; improved placement and management of intravenous lines and catheters; improved management of ventilated patients; ward deep cleaning; and greater emphasis on hospital cleanliness; as well as improved hand hygiene, has led to a dramatic fall in MRSA and $C$. difficile infection rates. However, while great improvements have been made it is difficult to say which particular measures have been the most effective. So the contribution of improved ward cleanliness to the overall reduction in HAls is difficult to quantify. Consequently, more research is needed to understand and quantify the role that ward cleaning plays in preventing HAls. 
One advance in recent years has been the trend towards a more multi-disciplinary approach to infection control. In particular, the involvement of engineers in infection control has led to advances in the application of technologies such as UVGI (Beggs and Sleigh, 2002, Noakes et. al. , 2004b, Noakes et. al. , 2004a, Beggs et. al. , 2000, Beggs, 2002, Cairns et. al. , 2001, Beggs et. al. , 2006c), negative air ionization (Kerr et. al. , 2006, Fletcher et. al. , 2007, Fletcher et. al. , 2008), and hydrogen peroxide terminal disinfection (Otter et. al. , 2006, Otter et. al. , 2007, Otter et. al. , 2008, Otter and French, 2009). While these technologies have merit, engineers can make the mistake of thinking that HAls can be eliminated using a quick-fix technological solution. Indeed, many devices have not delivered reductions in $\mathrm{HAI}$, primarily because their inventors failed to understand the complexity of the epidemiological systems associated with HAl. Having said this, if used appropriately as part of a multi-faceted approach to infection control, some of these environmental technologies may prove to be an important part of the solution. It is critical for engineers and others involved in technological solutions to bear in mind that the ultimate success or failure of an intervention is likely to depend more on the human element than the capability of the technology.

The simple calculation presented in section 4.1 above, suggests that aerial dissemination of bacteria may be a much greater problem than has been hitherto recognized. If staphylococci are being deposited onto surfaces from air at a rate $>50$ bacteria $/ \mathrm{m}^{2}$ per second, as the calculation indicates, it would suggest that aerial dissemination may be the principal mechanism by which contamination of the clinical environment occurs. Although the clinical relevance of aerial dissemination is not known, there is good reason for believing that it may be important. Ayliffe et al (Ayliffe et. al., 1999) reported that sterile gauze and forceps laid on a horizontal surface, became readily contaminated by bacteria through aerial dissemination after bed making and curtain shaking. Das et al. (Das et. al., 2002) implicated heavily contaminated bed curtains in an outbreak of Acinetobacter baumanii, which when moved promoted the airborne spread of Acinetobacter species. Similarly, Weernink et al. (Weernink et. al., 1995) implicated feather pillows in the aerial dispersal of Acinetobacter species. Boyce et al (Boyce et. al., 1997) found that $42 \%$ of personnel who had no direct contact with MRSA patients, but had touched contaminated surfaces within the ward space, contaminated their gloves with MRSA. Furthermore, Noble et al. (Noble, 1981) found that the size distribution of particles containing $S$. aureus was approximately $4-25 \mu \mathrm{m}$, which is roughly the size of skin squamae and 
well in excess of the size of single $S$. aureus cells (i.e. about $1 \mu \mathrm{m}$ diameter). Noble et al. therefore surmised that most of the airborne $S$. aureus organisms were carried on skin squamae. Given that humans liberate $>2 \times 10^{8}$ skin squamae into the air every day (Milstone, 2004), Noble et al. concluded that in many people a closed loop exists in which contaminated skin squamae are released into the air; they become impacted on the nasal turbinates; $S$. aureus grows on the nasal mucosa; hands then touch the nose and $S$. aureus bacteria are transferred to the skin; they colonize the skin and are ultimately disseminated back into the air on skin squamae.

The role of environmental contamination in the spread of Gram-negative bacterial infection is one that is becoming increasingly recognized. The ease with which contaminated sanitary fittings can lead to both the contamination of HCWs and the generation of aerosols containing Gram-negative bacteria is aptly illustrated by Doring et al. (Doring et. al., 1991). They found $81 \%$ of sinks in a children's hospital to be contaminated with $P$. aeruginosa, something that contributed to the colonization of the hands of $42.5 \%$ of the HCWs on duty. Doring et al's study highlights the threat that sanitary fittings can pose to patient safety if they become contaminated. In critical care settings where patients are immunocompromised, the presence of contaminated sanitary fittings can easily lead to outbreaks of Gram-negative bacterial infection. Investigating a cluster of Burkholderia cepacia complex colonization in ventilated pediatric patients, Lucero et al (Lucero et. al., 2011) identified tap water from hospital sinks as the likely mode of transmission. While they could not explain the exact mechanisms involved, the emergence of new cases stopped only after staff ended the practice of using tap water for oral and tracheostomy care. The link between clinical outcome and environmental contamination is further highlighted in an interesting study by Ryan et al (Ryan et. al., 2011), who used ultraviolet light to irradiate cooling coils in an air-conditioning system serving a NICU. They found the cooling coils and condensate drain to be heavily colonized with Gram-negative bacterial species; as were the environmental surfaces and sink traps in the NICU. However, after six months of ultraviolet irradiation, both the air conditioning units and the environmental surfaces were culture negative. Furthermore, they found that patient tracheal colonization greatly reduced with the introduction of ultraviolet irradiation, as did the incidence of VAP. From this they surmised that airborne Gramnegative pathogens were being widely disseminated by the air-conditioning system and contributing to both surface contamination and patient colonization. 
Given the magnitude of the HAl problem and the complexities of the systems involved, it is perhaps worth analyzing the ways in which microbes colonize the built environment (Kelley and Gilbert, 2013). Recently, researchers have sought to understand, from first principles, the microbial ecosystem that exists within hospitals, the so-called 'hospital microbiome' (Smith et. al. , 2013, Arnold, 2014). In the same way that antibiotics disrupt the normal microflora of the human body, constant attempts to 'sterilize' the clinical environment may in fact be removing a benign microbiome, which is capable of controlling and out-competing pathogenic species, only to replacing it with a microbial ecosystem that is more harmful to patients (Arnold, 2014). The fact that a sterile ward environment can become colonized with MRSA within 24-hours of admitting patients (Hardy et. al. , 2007), illustrates just how much 'nature abhors a vacuum'. Bacterial communities within indoor environments have been found to harbour microbial species not commonly found outdoors (Tringe et. al. , 2008). Kembel et al (Kembel et. al. , 2012) found that several bacterial taxa, commonly found in the human microbiome (including members of the families Burkholderiaceae, Pseudomonadaceae and Staphylococcaceae), were abundant in indoor air, especially in mechanically ventilated rooms, but nearly absent from outdoor air. Given that these species are commonly associated with humans as commensals or pathogens, they concluded that humans are important dispersal vectors for bacteria that colonize the built environment. Kemble et al (Kembel et. al., 2012) also found that building attributes, such as the source of ventilation air, relative humidity and temperature, correlated with the composition of indoor airborne bacterial communities, with the highest phylogenic diversity found in the outdoor air and the lowest in rooms that were mechanically ventilated. This suggests that buildings can select for certain bacterial species, with the result that the indoor microbial ecosystem is less diverse and strongly influenced by the microflora of humans who spend as much as $90 \%$ of their lives indoors (Kelley and Gilbert, 2013). As such, it may be worth reappraising the way hospital buildings are designed. Reducing direct contact with the outdoor environment may not always be the best strategy for the management of bacterial pathogens (Kembel et. al., 2012). By creating an indoor environment that reflects the make-up of the outdoor air, it may be possible to create a more benign hospital microbiome. This challenges the assumption, held in many parts of the world, that hospitals should be sealed airconditioned buildings, in which humidity and temperature are tightly controlled. It also presents a challenge to those seeking to minimize ventilation rates in order to save energy. However, it offers the possibility that if appropriate ventilation strategies can be identified, that move the hospital microbiome closer to that found in the outdoor 
environment, then it may be possible to create an ecosystem which reduces the risk of patients acquiring a HAI.

Given increased emphasis on hospital hygiene in recent years, it is surprising that the whole issue of ventilation and its influence on the hospital microbiome has been largely overlooked. There is mounting evidence that the aerial dissemination of bacteria is a widespread phenomenon within the clinical environment. Yet little is known about how this influences the microbiome as a whole, or indeed the spread of HAl. Although environmental contamination has been implicated in some outbreaks of Gram-negative bacterial infection (Pinna et. al., 2009, McDonald et. al., 1998), the full extent to which it contributes to $\mathrm{HAl}$ is not known. For example, one might intuitively think that heavy contamination of air ductwork systems would pose a threat to patient safety. However, because few epidemiological studies have been undertaken specifically to investigate this subject, there is little evidence to substantiate this claim. Consequently, it is difficult to make any evidence-based decisions regarding optimum strategies to control HAI. Clearly, a better understanding of the microbial ecosystem within hospitals would be advantageous. A deeper understanding of the ways in which microbes disperse and colonize the clinical environment, together with the factors that influence this process, would provide a strong evidence base, which would be helpful in formulating future inflection control strategies.

\section{Acknowledgement}

At the Healthy Buildings 2012 conference in Brisbane in July 2012 a debate was conducted and attended by many experts on infection control and building design. This debate explored the role of environmental contamination in the transmission of infection within healthcare facilities. This paper arises from that debate and we are thankful to all those who contributed to it. In particular we thank the panel members, Tricia Coward, Yuguo Li, Jeremy Stamkos and Erica Stewart for their helpful contributions. This work was also supported by a Queensland University of Technology, IHBI Collaborative Research Development Grant titled, How transmissible is influenza by the airborne route? Luke Knibbs acknowledges an NHMRC Early Career (Australian Public Health) Fellowship (APP1036620). 


\section{References}

A.I.A. (2001) Guidelines for design and construction of hospital and health care facilities, Washington, DC, American Institution of Architects.

A.S.H.R.A.E. (2003) HVAC design manual for hospitals and clinics, Atlanta, American Society of Heating, Refrigeration and Air-conditioning Engineers (ASHRAE).

Allen, K.D. and Green, H.T. (1987) Hospital outbreak of multi-resistant Acinetobacter anitratus: an airborne mode of spread?, J Hosp Infect, 9, 110-119.

Arnold, C. (2014) Rethinking sterile: the hospital microbiome, Environ Health Perspect, 122, A182-187.

Ayliffe, G.A.J., Babb, J.R. and Taylor, L.J. (1999) Hospital-acquired infection principles and prevention, Butterworth-Heinemann.

Batterman, S.A. and Burge, H. (1995) HVAC systems as emission sourses affecting indoor air quality: a critical review, HVAC\&R Research, 1, 61-80.

Beggs, C.B. (2002) A quantitative method for evaluating the photoreactivation of ultraviolet damaged microorganisms, Photochem Photobiol Sci, 1, 431-437.

Beggs, C.B. (2003a) The airborne transmission of infection in hospital buildings: fact or fiction?, Indoor and Built Environment 12, 1-10.

Beggs, C.B. (2003b) The airborne transmission of infection in hospital buildings: fact or fiction?, Indoor and Built Environment, 12, 9-18.

Beggs, C.B., Kerr, K.G., Donnelly, J.K., Sleigh, P.A., Mara, D.D. and Cairns, G. (2000) The resurgence of tuberculosis in the tropics. An engineering approach to the control of Mycobacterium tuberculosis and other airborne pathogens: a UK hospital based pilot study, Trans $R$ Soc Trop Med Hyg, 94, 141-146.

Beggs, C.B., Kerr, K.G., Noakes, C.J., Hathway, E.A. and Sleigh, P.A. (2008a) The ventilation of multiple-bed hospital wards: review and analysis, Am J Infect Control, 36, 250-259.

Beggs, C.B., Kerr, K.G., Snelling, A.M. and Sleigh, P.A. (2006a) Acinetobacter spp. and the clinical environment, Indoor and Built Environment, 15, 19-24.

Beggs, C.B., Noakes, C.J., Shepherd, S.J., Kerr, K.G., Sleigh, P.A. and Banfield, K. (2006b) The influence of nurse cohorting on hand hygiene effectiveness, $A m$ $J$ Infect Control, 34, 621-626.

Beggs, C.B., Noakes, C.J., Sleigh, P.A., Fletcher, L.A. and Kerr, K.G. (2006c) Methodology for determining the susceptibility of airborne microorganisms to irradiation by upper-room UVGI system, Journal of Aerosol Science, 37, 885902.

Beggs, C.B., Shepherd, S.J. and Kerr, K.G. (2008b) Increasing the frequency of hand washing by healthcare workers does not lead to commensurate reductions in staphylococcal infection in a hospital ward, BMC Infect Dis.

Beggs, C.B., Shepherd, S.J. and Kerr, K.G. (2009) How does healthcare worker hand hygiene behaviour impact upon the transmission of MRSA between patients?: an analysis using a Monte Carlo model, BMC Infect Dis, 9, 64.

Beggs, C.B. and Sleigh, P.A. (2002) A quantitative method for evaluating the germicidal effect of upper room UV fields, Journal of Aerosol Science, 33, 1681-1699.

Bhalla, A., Pultz, N.J., Gries, D.M., Ray, A.J., Eckstein, E.C., Aron, D.C. and Donskey, C.J. (2004) Acquisition of nosocomial pathogens on hands after contact with environmental surfaces near hospitalized patients, Infect Control Hosp Epidemiol, 25, 164-167. 
Boyce, J.M., Potter-Bynoe, G., Chenevert, C. and King, T. (1997) Environmental contamination due to methicillin-resistant Staphylococcus aureus: possible infection control implications, Infect Control Hosp Epidemiol, 18, 622-627.

Breathnach, A.S., Cubbon, M.D., Karunaharan, R.N., Pope, C.F. and Planche, T.D. (2012) Multidrug-resistant Pseudomonas aeruginosa outbreaks in two hospitals: association with contaminated hospital waste-water systems, $J$ Hosp Infect, 82, 19-24.

Buttner, M.P., Cruz-Perez, P., Garrett, P.J. and Stetzenbach, L.D. (1999) Dispersal of fungal spores from three types of air handling system duct material, Aerobiologia, 15, 1-8.

Cairns, G., Kerr, K.G., Beggs, C.B., Sleigh, P.A., Mooney, L., Keig, P. and Donnelly, J.K. (2001) Susceptibility of Burkholderia cepacia and other pathogens of importance in cystic fibrosis to u.v. light, Lett Appl Microbiol, 32, 135-138.

Cefai, C., Richards, J., Gould, F.K. and Mcpeake, P. (1990) An outbreak of Acinetobacter respiratory tract infection resulting from incomplete disinfection of ventilatory equipment, $J$ Hosp Infect, 15, 177-182.

Collins, B.J. (1988) The hospital environment: how clean should a hospital be?, J Hosp Infect, 11 Suppl A, 53-56.

Cotterill, S. and Al., E. (1996) An unusual source for an outbreak of methicillinresistant Staphylococcus aureus, Journal of Hospital Infection, 32, 207 - 216.

Curtis, L., Cali, S., Conroy, L., Baker, K., Ou, C.H., Hershow, R., Norlock-Cruz, F. and Scheff, P. (2005) Aspergillus surveillance project at a large tertiary-care hospital, J Hosp Infect, 59, 188-196.

D.O.H. (2007) Heating and ventilating systems - Health Technical Memorandum 0301: Specialist ventilation for healthcare premises, London, The Stationary Office.

D.O.H. (2008) From deep clean to keep clean, London, The Stationary Office.

Dancer, S.J. (2004) How do we assess hospital cleaning? A proposal for microbiological standards for surface hygiene in hospitals, J Hosp Infect, 56, 10-15.

Dancer, S.J. (2008) Importance of the environment in meticillin-resistant Staphylococcus aureus acquisition: the case for hospital cleaning, Lancet Infect Dis, 8, 101-113.

Dancer, S.J., White, L.F., Lamb, J., Girvan, E.K. and Robertson, C. (2009) Measuring the effect of enhanced cleaning in a UK hospital: a prospective cross-over study, BMC Med, 7, 28.

Das, I., Lambert, P., Hill, D., Noy, M., Bion, J. and Elliott, T. (2002) Carbapenemresistant Acinetobacter and role of curtains in an outbreak in intensive care units, J Hosp Infect, 50, 110-114.

De Abreu, P.M., Farias, P.G., Paiva, G.S., Almeida, A.M. and Morais, P.V. (2014) Persistence of microbial communities including Pseudomonas aeruginosa in a hospital environment: a potential health hazard, BMC Microbiol, 14, 118.

Dekker, T.J.A. and Van Den Broek, P.J. (2010) Successful control of MRSA spread in Dutch hospitals, International Journal of Infection Control, 6, 1-4.

Denton, M., Rajgopal, A., Mooney, L., Qureshi, A., Kerr, K.G., Keer, V., Pollard, K., Peckham, D.G. and Conway, S.P. (2003) Stenotrophomonas maltophilia contamination of nebulizers used to deliver aerosolized therapy to inpatients with cystic fibrosis, J Hosp Infect, 55, 180-183.

Didiodato, G. (2013) Has improved hand hygiene compliance reduced the risk of hospital-acquired infections among hospitalized patients in Ontario? Analysis of publicly reported patient safety data from 2008 to 2011, Infect Control Hosp Epidemiol, 34, 605-610.

Doring, G., Ulrich, M., Muller, W., Bitzer, J., Schmidt-Koenig, L., Munst, L., Grupp, H., Wolz, C., Stern, M. and Botzenhart, K. (1991) Generation of Pseudomonas aeruginosa aerosols during handwashing from contaminated sink drains, 
transmission to hands of hospital personnel, and its prevention by use of a new heating device, Zentralbl Hyg Umweltmed, 191, 494-505.

Duckro, A.N., Blom, D.W., Lyle, E.A., Weinstein, R.A. and Hayden, M.K. (2005) Transfer of vancomycin-resistant enterococci via health care worker hands, Arch Intern Med, 165, 302-307.

Ebenezer, K., James, E.J., Michael, J.S., Kang, G. and Verghese, V.P. (2011) Ventilator-associated Acinetobacter baumannii pneumonia, Indian Pediatr, 48, 964-966.

Engelhart, S., Krizek, L., Glasmacher, A., Fischnaller, E., Marklein, G. and Exner, M. (2002) Pseudomonas aeruginosa outbreak in a haematology-oncology unit associated with contaminated surface cleaning equipment, J Hosp Infect, 52, 93-98.

Farrington, M., Redpath, C., Trundle, C., Coomber, S. and Brown, N.M. (1998) Winning the battle but losing the war: methicillin-resistant Staphylococcus aureus (MRSA) infection at a teaching hospital, Qjm, 91, 539-548.

Fawley, W.N., Freeman, J. and Wilcox, M.H. (2003) Evidence to support the existence of subgroups within the UK epidemic Clostridium difficile strain (PCR ribotype 1), J Hosp Infect, 54, 74-77.

Fawley, W.N. and Wilcox, M.H. (2001) Molecular epidemiology of endemic Clostridium difficile infection, Epidemiol Infect, 126, 343-350.

Fletcher, L.A., Gaunt, L.F., Beggs, C.B., Shepherd, S.J., Sleigh, P.A., Noakes, C.J. and Kerr, K.G. (2007) Bactericidal action of positive and negative ions in air, BMC Microbiol, 7, 32.

Fletcher, L.A., Noakes, C.J., Sleigh, P.A., Beggs, C.B. and Shepherd, S.J. (2008) Air ion behavior in ventilated rooms, Indoor and Built Environment, 17, 173-182.

Gerner-Smidt, P. (1987) Endemic occurrence of Acinetobacter calcoaceticus biovar anitratus in an intensive care unit, J Hosp Infect, 10, 265-272.

Greene, V.W., Bond, R.G. and Michaelsen, G.S. (1960) Air handling systems must be planned to reduce the spread of infection, Mod Hosp, 95, 136-144.

H.P.A. (2012a) Summary points on Clostridium difficile infections (CDI), London, Health Protection Agency.

H.P.A. (2012b) Summary points on meticillin resistant Staphylococcus aureus (MRSA) bacteraemia, London, Health Protection Agency.

Hardy, K.J., Gossain, S., Henderson, N., Drugan, C., Oppenheim, B.A., Gao, F. and Hawkey, P.M. (2007) Rapid recontamination with MRSA of the environment of an intensive care unit after decontamination with hydrogen peroxide vapour, J Hosp Infect, 66, 360-368.

Hardy, K.J., Oppenheim, B.A., Gossain, S., Gao, F. and Hawkey, P.M. (2006) A study of the relationship between environmental contamination with methicillin-resistant Staphylococcus aureus (MRSA) and patients' acquisition of MRSA, Infect Control Hosp Epidemiol, 27, 127-132.

Hathway, E.A., Noakes, C.J. and Sleigh, P.A. (2011) CFD simulation of airborne pathogen transport due to human activities, Building and Environment, 46, 2500-2511.

Hathway, E.A., Sleigh, P.A. and Noakes, C.J. (2007) CFD modelling of transient pathogen release in indoor environments due to human activity.

Hayden, M.K., Blom, D.W., Lyle, E.A., Moore, C.G. and Weinstein, R.A. (2008) Risk of hand or glove contamination after contact with patients colonized with vancomycin-resistant enterococcus or the colonized patients' environment, Infect Control Hosp Epidemiol, 29, 149-154.

Holopainen, R., Asikainen, V., Tuomainen, M., Bjorkroth, M., Pasanen, P. and Seppanen, O. (2003) Effectiveness of duct cleaning methods on newly installed duct surfaces, Indoor Air, 13, 212-222.

Horner, W.E. (2006) Managing building-related Aspergillus exposure, Medical Mycology, 44 (Sup. 1), S33-S38. 
Hota, B. (2004) Contamination, disinfection, and cross-colonization: Are hospital surfaces reservoirs for nosocomial infection?, Clin Infect Dis, 39, 1182-1189.

Houang, E.T., Chu, Y.W., Leung, C.M., Chu, K.Y., Berlau, J., Ng, K.C. and Cheng, A.F. (2001) Epidemiology and infection control implications of Acinetobacter spp. in Hong Kong, J Clin Microbiol, 39, 228-234.

Houk, V.N. (1980) Spread of tuberculosis via recirculated air in a naval vessel: the Byrd study, Ann N Y Acad Sci, 353, 10-24.

Hutchinson, G.R., Parker, S., Pryor, J.A., Duncan-Skingle, F., Hoffman, P.N., Hodson, M.E., Kaufmann, M.E. and Pitt, T.L. (1996) Home-use nebulizers: a potential primary source of Burkholderia cepacia and other colistin-resistant, gram-negative bacteria in patients with cystic fibrosis, J Clin Microbiol, 34, 584-587.

Jadhav, S., Sahasrabudhe, T., Kalley, V. and Gandham, N. (2013) The microbial colonization profile of respiratory devices and the significance of the role of disinfection: a blinded study, J Clin Diagn Res, 7, 1021-1026.

Jarvis, S., Ind, P.W., Thomas, C., Goonesekera, S., Haffenden, R., Abdolrasouli, A., Fiorentino, F. and Shiner, R.J. (2014) Microbial contamination of domiciliary nebulisers and clinical implications in chronic obstructive pulmonary disease, BMJ Open Resp Res, 1, e000018.

Kelley, S.T. and Gilbert, J.A. (2013) Studying the microbiology of the indoor environment, Genome Biol, 14, 202.

Kembel, S.W., Jones, E., Kline, J., Northcutt, D., Stenson, J., Womack, A.M., Bohannan, B.J., Brown, G.Z. and Green, J.L. (2012) Architectural design influences the diversity and structure of the built environment microbiome, Isme J, 6, 1469-1479.

Kerr, K.G., Beggs, C.B., Dean, S.G., Thornton, J., Donnelly, J.K., Todd, N.J., Sleigh, P.A., Qureshi, A. and Taylor, C.C. (2006) Air ionisation and colonisation/infection with methicillin-resistant Staphylococcus aureus and Acinetobacter species in an intensive care unit, Intensive Care Med, 32, 315317.

King, M.F., Noakes, C.J., Sleigh, P.A. and Camargo-Valero, M.A. (2013) Bioaerosol deposition in single and two-bed hospital rooms: a numerical and experimental study, Buidling and Environment, 59, 436-447.

Kotsanas, D., Wijesooriya, W.R., Korman, T.M., Gillespie, E.E., Wright, L., Snook, K., Williams, N., Bell, J.M., Li, H.Y. and Stuart, R.L. (2013) "Down the drain": carbapenem-resistant bacteria in intensive care unit patients and handwashing sinks, Med J Aust, 198, 267-269.

Kuehn, T.H. (2003) Airborne infection control in health care facilities, Journal of Solar Energy Engineering, 125, 366-371.

Kumari, D.N., Haji, T.C., Keer, V., Hawkey, P.M., Duncanson, V. and Flower, E. (1998) Ventilation grilles as a potential source of methicillin-resistant Staphylococcus aureus causing an outbreak in an orthopaedic ward at a district general hospital, J Hosp Infect, 39, 127-133.

Lentino, J.R., Rosenkranz, M.A., Michaels, J.A., Kurup, V.P., Rose, H.D. and Rytel, M.W. (1982) Nosocomial aspergillosis: a retrospective review of airborne disease secondary to road construction and contaminated air conditioners, Am J Epidemiol, 116, 430-437.

Lucero, C.A., Cohen, A.L., Trevino, I., Rupp, A.H., Harris, M., Forkan-Kelly, S., Noble-Wang, J., Jensen, B., Shams, A., Arduino, M.J., Lipuma, J.J., Gerber, S.I. and Srinivasan, A. (2011) Outbreak of Burkholderia cepacia complex among ventilated pediatric patients linked to hospital sinks, Am J Infect Control, 39, 775-778.

Lundholm, I.M. (1982) Comparison of methods for quantitative determinations of airborne bacteria and evaluation of total viable counts, Appl Environ Microbiol, 44, 179-183. 
Lutz, B.D., Jin, J., Rinaldi, M.G., Wickes, B.L. and Huycke, M.M. (2003) Outbreak of invasive Aspergillus infection in surgical patients, associated with a contaminated air-handling system, Clin Infect Dis, 37, 786-793.

Maki, D.G., Alvarado, C.J., Hassemer, C.A. and Zilz, M.A. (1982) Relation of the inanimate hospital environment to endemic nosocomial infection, $N$ Engl J Med, 307, 1562-1566.

Malamou-Ladas, H., O'farrell, S., Nash, J.Q. and Tabaqchali, S. (1983) Isolation of Clostridium difficile from patients and the environment of hospital wards, $J$ Clin Pathol, 36, 88-92.

Mastro, T.D., Fields, B.S., Breiman, R.F., Campbell, J., Plikaytis, B.D. and Spika, J.S. (1991) Nosocomial Legionnaires' disease and use of medication nebulizers, $J$ Infect Dis, 163, 667-671.

Maus, R., Goppelsroder, A. and Umhauer, H. (2001) Survival of bacteria and mold spores in air filter media, Atmos Environ, 35, 105-113.

Mcdonald, L.C., Walker, M., Carson, L., Arduino, M., Aguero, S.M., Gomez, P., Mcneil, P. and Jarvis, W.R. (1998) Outbreak of Acinetobacter spp. bloodstream infections in a nursery associated with contaminated aerosols and air conditioners, Pediatr Infect Dis J, 17, 716-722.

Mcgowan, J.E., Jr. (1981) Environmental factors in nosocomial infection-a selective focus, Rev Infect Dis, 3, 760-769.

Milstone, L.M. (2004) Epidermal desquamation, J Dermatol Sci, 36, 131-140.

N.P.S.A (2007) The national specifications for cleanliness in the NHS: a framework for setting and measuring performance outcomes, London, The National Patient Safety Agency.

Nardell, E.A., Keegan, J., Cheney, S.A. and Etkind, S.C. (1991) Airborne infection. Theoretical limits of protection achievable by building ventilation, Am Rev Respir Dis, 144, 302-306.

Noakes, C.J., Beggs, C.B. and Sleigh, P.A. (2004a) Effect of room mixing and ventilation strategy on the performance of upper room ultraviolet germicidal irradiation systems.

Noakes, C.J., Beggs, C.B. and Sleigh, P.A. (2004b) Modelling the performance of upper room ultraviolet germicidal irradiation devices in ventilated rooms: Comparison of analytical and CFD methods, Indoor and Built Environment, 13, 477-488.

Noble, W.C. (1962) The dispersal of staphylococci in hospital wards, J Clin Pathol, 15, 552-558.

Noble, W.C. (1981) Dispersal of microorganisms from skin, Microbiology of human skin, London, Lloyd-Luke Ltd., 79-85.

Noble, W.C. and Davies, R.R. (1965) Studies on the Dispersal of Staphylococci, J Clin Pathol, 18, 16-19.

Obbard, J.P. and Fang, L.S. (2003) Airborne concentrations of bacteria in a hospital environment in Singapore, Water, Air, and Soil Pollution, 144, 333-341.

Oelberg, D.G., Joyner, S.E., Jiang, X., Laborde, D., Islam, M.P. and Pickering, L.K. (2000) Detection of pathogen transmission in neonatal nurseries using DNA markers as surrogate indicators, Pediatrics, 105, 311-315.

Oren, I., Haddad, N., Finkelstein, R. and Rowe, J.M. (2001) Invasive pulmonary aspergillosis in neutropenic patients during hospital construction: before and after chemoprophylaxis and institution of HEPA filters, Am J Hematol, 66, 257-262.

Otter, J.A., Chewins, J., Windsor, D. and Windsor, H. (2008) Microbiological contamination in cell culture: a potential role for hydrogen peroxide vapour (HPV)?, Cell Biol Int, 32, 326-327.

Otter, J.A., Cummins, M., Ahmad, F., Van Tonder, C. and Drabu, Y.J. (2007) Assessing the biological efficacy and rate of recontamination following hydrogen peroxide vapour decontamination, J Hosp Infect, 67, 182-188. 
Otter, J.A. and French, G.L. (2009) Survival of nosocomial bacteria and spores on surfaces and inactivation by hydrogen peroxide vapor, J Clin Microbiol, 47, 205-207.

Otter, J.A., French, G.L., Adams, N.M., Watling, D. and Parks, M.J. (2006) Hydrogen peroxide vapour decontamination in an overcrowded tertiary care referral centre: some practical answers, J Hosp Infect, 62, 384-385.

Pearson, A. (2009) Historical and changing epidemiology of healthcare-associated infections, J Hosp Infect, 73, 296-304.

Phillips, I. (1967) Pseudomonas aeruginosa respiratory tract infections in patients receiving mechanical ventilation, $J$ Hyg (Lond), 65, 229-235.

Pinna, A., Usai, D., Sechi, L.A., Zanetti, S., Jesudasan, N.C., Thomas, P.A. and Kaliamurthy, J. (2009) An outbreak of post-cataract surgery endophthalmitis caused by Pseudomonas aeruginosa, Ophthalmology, 116, 2321-2326 e2321-2324.

Ray, A.J., Hoyen, C.K., Taub, T.F., Eckstein, E.C. and Donskey, C.J. (2002) Nosocomial transmission of vancomycin-resistant enterococci from surfaces, Jama, 287, 1400-1401.

Redding, P.J. and Mcwalter, P.W. (1980) Pseudomonas fluorescens cross-infection due to contaminated humidifier water, Br Med J, 281, 275.

Rhame, F.S. (1998) The inanimate environment, In: Bennett, J. V. and Brachman, P. S. (eds) Hospital Infections, Lippincott-Raven Publishers.

Roberts, D. and Marks, R. (1980) The determination of regional and age variations in the rate of desquamation: a comparison of four techniques, J Invest Dermatol, 74, 13-16.

Roberts, K., Hathway, A., Fletcher, L.A., Beggs, C.B., Elliott, M.W. and Sleigh, P.A. (2006) Bioaerosol production on a respiratory ward, Indoor and Built Environment, 15, 35-40.

Roberts, K., Smith, C.F., Snelling, A.M., Kerr, K.G., Banfield, K.R., Sleigh, P.A. and Beggs, C.B. (2008) Aerial dissemination of Clostridium difficile spores, BMC Infect Dis, 8, 7.

Rutala, W.A., Katz, E.B., Sherertz, R.J. and Sarubbi, F.A., Jr. (1983) Environmental study of a methicillin-resistant Staphylococcus aureus epidemic in a burn unit, $J$ Clin Microbiol, 18, 683-688.

Ryan, R.M., Wilding, G.E., Wynn, R.J., Welliver, R.C., Holm, B.A. and Leach, C.L. (2011) Effect of enhanced ultraviolet germicidal irradiation in the heating ventilation and air conditioning system on ventilator-associated pneumonia in a neonatal intensive care unit, J Perinatol, 31, 607-614.

Sherertz, R.J. and Sullivan, M.L. (1985) An outbreak of infections with Acinetobacter calcoaceticus in burn patients: contamination of patients' mattresses, $J$ Infect Dis, 151, 252-258.

Shiomori, T., Miyamoto, H. and Makishima, K. (2001) Significance of airborne transmission of methicillin-resistant Staphylococcus aureus in an otolaryngology-head and neck surgery unit, Arch Otolaryngol Head Neck Surg, 127, 644-648.

Shiomori, T., Miyamoto, H., Makishima, K., Yoshida, M., Fujiyoshi, T., Udaka, T., Inaba, T. and Hiraki, N. (2002) Evaluation of bedmaking-related airborne and surface methicillin-resistant Staphylococcus aureus contamination, $J$ Hosp Infect, 50, 30-35.

Silvestri, L., Petros, A.J., Sarginson, R.E., De La Cal, M.A., Murray, A.E. and Van Saene, H.K. (2005) Handwashing in the intensive care unit: a big measure with modest effects, J Hosp Infect, 59, 172-179.

Simmons, R.B. and Crow, S.A. (1995) Fungal colonization of air filters for use in heating, ventilating and air conditioning (HVAC) systems, J Ind Microbiol, 14, 41-45. 
Smith, D., Alverdy, J., An, G., Coleman, M., Garcia-Houchins, S., Green, J., Keegan, K., Kelley, S.T., Kirkup, B.C., Kociolek, L., Levin, H., Landon, E., Olsiewski, P., Knight, R., Siegel, J., Weber, S. and Gilbert, J. (2013) The Hospital Microbiome Project: Meeting Report for the 1st Hospital Microbiome Project Workshop on sampling design and building science measurements, Chicago, USA, June 7th-8th 2012, Stand Genomic Sci, 8, 112-117.

Solberg, C.O. (1965) A study of carriers of Staphylococcus aureus, Acta. Med. Scand. , 178 (suppl.), 436.

Stone, S.P., Fuller, C., Savage, J., Cookson, B., Hayward, A., Cooper, B., Duckworth, G., Michie, S., Murray, M., Jeanes, A., Roberts, J., Teare, L. and Charlett, A. (2012) Evaluation of the national Cleanyourhands campaign to reduce Staphylococcus aureus bacteraemia and Clostridium difficile infection in hospitals in England and Wales by improved hand hygiene: four year, prospective, ecological, interrupted time series study, Bmj, 344, e3005.

Talon, D., Thouverez, M. and Bertrand, X. (2009) Is there a threshold above which hand-rub solution consumption is efficient for decreasing MRSA incidence?, $J$ Hosp Infect, 72, 178-179.

Thornton, T., Fletcher, L.A., Beggs, C.B., Elliott, M.W. and Kerr, K.G. (2004) Airborne microflora in a respiratory ward.

Tiemersma, E.W., Monnet, D.L., Bruinsma, N., Skov, R., Monen, J.C. and Grundmann, H. (2005) Staphylococcus aureus bacteremia, Europe, Emerg Infect Dis, 11, 1798-1799.

Toivola, M., Nevalainen, A. and Alm, S. (2004) Personal exposures to particles and microbes in relation to microenvironmental concentrations, Indoor Air, 14, 351-359.

Trautmann, M., Michalsky, T., Wiedeck, H., Radosavljevic, V. and Ruhnke, M. (2001) Tap water colonization with Pseudomonas aeruginosa in a surgical intensive care unit (ICU) and relation to Pseudomonas infections of ICU patients, Infect Control Hosp Epidemiol, 22, 49-52.

Tringe, S.G., Zhang, T., Liu, X., Yu, Y., Lee, W.H., Yap, J., Yao, F., Suan, S.T., Ing, S.K., Haynes, M., Rohwer, F., Wei, C.L., Tan, P., Bristow, J., Rubin, E.M. and Ruan, Y. (2008) The airborne metagenome in an indoor urban environment, PLoS One, 3, e1862.

Van Rijen, M.M. and Kluytmans, J.A. (2009) Costs and benefits of the MRSA Search and Destroy policy in a Dutch hospital, Eur J Clin Microbiol Infect Dis, 28, 1245-1252.

Walsh, T.J. and Dixon, D.M. (1989) Nosocomial aspergillosis: environmental microbiology, hospital epidemiology, diagnosis and treatment, Eur $J$ Epidemiol, 5, 131-142.

Weernink, A., Severin, W.P., Tjernberg, I. and Dijkshoorn, L. (1995) Pillows, an unexpected source of Acinetobacter, J Hosp Infect, 29, 189-199.

Wilson, R.D., Huang, S.J. and Mclean, A.S. (2004) The correlation between airborne methicillin-resistant Staphylococcus aureus with the presence of MRSA colonized patients in a general intensive care unit, Anaesth Intensive Care, 32, 202-209.

Wong, L.T., Chan, W.Y., Nmui, K.W. and Lai, A.C.K. (2010) An experimental and numerical study on deposition of bioaerosols in a scaled chamber, Aerosol Sci Technol, 44, 117-128.

Zuraimi, M.S. (2010) Is ventilation duct cleaning useful? A review of the scientific evidence, Indoor Air, 20, 445-457. 